\title{
Findings from a National Survey of Medicare Beneficiary Perspectives on the Medicare Part D Medication Therapy Management Standardized Format
}

\author{
Nicole J. Brandt, PharmD, MBA, BCGP; Catherine E. Cooke, PharmD, BCPS, PAHM; \\ Kriti Sharma, MD, MPH; Joshua Chou, PharmD; Mary Jo Carden, RPh, JD; Patty Kumbera, RPh; \\ and Karen Pellegrin, PhD, MBA
}

\begin{abstract}
BACKGROUND: The Medication Therapy Management (MTM) Program Standardized Format (SF) is a written summary of a comprehensive medication review (CMR) that must be provided to Medicare Part $D$ beneficiaries. Concerns have been raised regarding the number of pages of the SF, mailing costs, the static nature of the document, and the lack of integration into beneficiaries' electronic health records. To date, limited research exists on beneficiaries' perceptions of the SF.
\end{abstract}

OBJECTIVE: To evaluate the perspectives of beneficiaries regarding the utility of the SF to inform potential modifications for optimal use.

METHODS: An online survey, designed based on the standard approach to measuring patient satisfaction with health service attributes and previous qualitative research, was distributed through Medicare Part D plans to beneficiaries who had received a CMR in the past year. Survey distribution began July 1, 2018, and data collection ended on October 31, 2018. Descriptive statistics are reported for demographic information; health status; perceived value and helpfulness of the SF and its 3 components (cover letter, medication action plan [MAP], personal medication list [PML]); updates to the SF; alternate formatting; and integration of the SF into health records.

RESULTS: A total of 9,975 surveys were sent electronically by 4 Medicare Part D plans to beneficiaries who had received a CMR in the past year. Of the 434 unduplicated survey respondents (response rate of $4.3 \%$ ), $58.5 \%$ were aged 65 to 84 years; $60 \%$ identified themselves as white; and $49.1 \%$ had at least a college education. The most commonly reported comorbidities were diabetes $(50.5 \%)$ and high cholesterol $(43.1 \%)$, with $10.7 \%$ of respondents rating their health as "very good" or "excellent" and $27.4 \%$ choosing "poor" or "fair." Beneficiaries rated how well the SF helped improve different aspects of their medication management (e.g., solving medication-related problems, keeping track of medications, correctly using medications, and understanding why medications are being taken), with $40.8 \%-44.9 \%$ choosing "very good" to "excellent" for each aspect. Helpful sections included "What we talked about" and "What I need to do" for the MAP, and medication name, strength, dosage form, and "How and why I use the medication" for the PML. Less helpful were the fill-in sections of the MAP, with $48.6 \%$ reporting that they did not write in any information. In contrast, $44.7 \%$ of the participants noted that they updated their PML. A wallet card version of the PML, if available, would be used by $54.6 \%$ of participants. About one third of Medicare beneficiaries shared the SF with their doctor, and $26 \%$ of the participants gave copies of their medication summary to their relatives.

CONCLUSIONS: Fewer than half of the respondents perceived the SF as very good or excellent in helping them to manage their medications. This national survey provides Medicare beneficiary-focused evidence that more work is needed to improve the usability and portability of the SF. This can be achieved by allowing flexibility in the design of the SF, while including essential elements.

J Manag Care Spec Pharm. 2019;25(3):366-91

Copyright $\odot 2019$, Academy of Managed Care Pharmacy. All rights reserved.

\section{What is already known about this subject}

Medicare beneficiaries find the medication therapy management comprehensive medication review service valuable, yet the Standardized Format (SF) is not "memorable."

There is limited evidence about which aspects of the SF are valuable to Medicare beneficiaries and how the SF could be improved.

\section{What this study adds}

This study found that only $40.8 \%-44.9 \%$ of participants rated the SF as "very good" or "excellent" in helping to improve their medication management.

Within the SF, beneficiaries perceived the medication action plan (MAP) to be less useful than the personal medication list (PML), with $48.6 \%$ not writing in any information in the fill-in sections of the MAP

Study results showed that $44.7 \%$ of participants reported that they updated their PMLs and noted the most useful sections to be medication name, strength, dosage form, and "How and why I use the medication.

I n 2006, the Centers for Medicare \& Medicaid Services (CMS) began offering a prescription drug benefit known as Part D to Medicare beneficiaries. In addition to managing the coverage of specified medications, participating sponsors in the Part D program must provide eligible Medicare beneficiaries with access to medication therapy management (MTM) services. According to the requirements for MTM programs under 42 CFR section 423.153(d) of the Medicare Prescription Drug Benefit Manual, a Part D sponsor must have established an MTM program that (a) ensures optimum therapeutic outcomes for targeted beneficiaries through improved medication use, (b) reduces the risk of adverse events, (c) is developed in coordination with licensed and practicing pharmacists and physicians, (d) describes the resources and time required to implement the program and establishes the fees for MTM providers, and (e) may be furnished by pharmacists or other qualified providers. ${ }^{1}$ 
One part of the MTM program is the comprehensive medication review (CMR), an interactive session with the beneficiary and qualified MTM provider where medications are reviewed; drug therapy problems are identified; and a plan for resolution is developed. The CMR must be delivered face to face or using telehealth technologies by a licensed pharmacist or other qualified provider, with a written medication review and action plan and input from the prescriber as necessary and practical. Since January 1, 2013, all beneficiaries receiving a CMR were required to receive a written summary of the encounter using the MTM Standardized Format (SF). ${ }^{1}$ The goal of this requirement was to advance consistency in the CMR service by providing a template of expected content. ${ }^{2}$

Despite this requirement, barriers such as integration of the SF into electronic medical records and its lack of portability have decreased the potential utility of the CMR. Although there has been increased provider demand for electronic access to medication history and increased electronic exchange of health information among providers, ${ }^{3,4}$ the SF remains separate from the electronic medical record.

Beneficiaries have shared their perspectives on portability with CMS. In 2015, a survey of Medicare beneficiaries who had received a CMR found that one third could not recall receiving an SF, and $28 \%$ of those who remembered receiving one stated that they preferred a shorter personal medication list (PML) when they are taking a large number of medications. ${ }^{3}$ The utility of a long PML was examined in another survey of 9 Medicare beneficiaries who had also received a CMR. ${ }^{5}$ In the survey, 67\% of beneficiaries noted that they personally created a separate, smaller handwritten list of medications for reference, presumably because the PML was not meeting their needs.

Other stakeholders have also raised concerns about the SF. Sharing the perspective of those implementing the SF requirement, the Academy of Managed Care Pharmacy (AMCP) noted that the typical SF is " $10+$ pages and costs an average of $\$ 1.39$ to mail to the beneficiary." Furthermore, Snyder et al. (2018) noted that pharmacists and pharmacy staff at 3 of 4 MTM practices reported dissatisfaction with the SF, noting that it was cumbersome and overwhelming for patients. ${ }^{7}$

Because there is limited beneficiary-centered evidence about the SF, the objectives of this study were to understand beneficiary perceptions regarding the Medicare Part D MTM SF and to evaluate the utility of the SF to inform potential modifications for optimal use.

\section{Methods}

\section{Study Design and Data Collection}

The survey design was based on the standard approach for measuring patient satisfaction with health service attributes, as well as results obtained from previous research. ${ }^{8,9}$ In this approach, survey items reflect specific features of the episode of care, which, in our case, were the various aspects of the structure of the SF from the most recent CMR. Where appropriate, the response format of "excellent," "very good," "good," "fair," and "poor" was used rather than "very satisfied" to "very dissatisfied" because the former has been found to produce better psychometric properties. ${ }^{10}$ Global satisfaction items were also used to determine if any specific items were unrelated, indicating that specific feature was not likely a critical component of satisfaction with the overall episode of care, and which specific items were most strongly correlated, indicating those were likely the most critical components of satisfaction with the overall episode and, thus, priorities for improvement.

The emergent themes from the qualitative work included usefulness of certain SF sections, such as names of medications and how the patient should take them, and suggestions for additional sections, such as drug interactions, cheaper alternatives, and a priority listing of drugs. Another key theme was the suggestion for alternative methods or formats of delivery and more frequent updates. These themes were used to construct survey questions with multiple choices in 4 key focus areas: (1) overall value of the SF, (2) content and usability of the SF and its different sections, (3) delivery methods and updates, and (4) portability and sharing of the SF.

The survey was pilot tested based on the recommendations from a convenience sample of Medicare beneficiaries $(n=10)$ and selected committee members of the AMCP Advisory Group who had been involved with MTM research and survey design (authors Kumbera and Pellegrin). Testers were asked to comment on the flow, clarity, and time to complete the survey. The wording, content, and duration of the survey were revised. Another round of testing with Medicare beneficiaries $(n=5)$ and members of the MTM research and survey design team accepted the revised survey, noting that it took approximately 20 minutes to complete.

The final survey was a structured questionnaire with 42 multiple-choice questions that covered the value and perception of the SF components (i.e., cover letter, MAP [medication action plan], and PML); the utility of individual sections within each component; the delivery of the SF; updates to the SF; and integration with health records (see Appendix, available in online article). There were 8 questions related to utility, 4 questions on use-based rating of the SF, 12 questions on the 3 components of the SF, and 3 questions on each component on the delivery and overall rating of the document. Most questions were perception based and had the potential responses of "yes," "no," or "not sure." For the rating questions, the participants could choose 1 of 5 options: "poor," "fair," "good," "very good," and "excellent." Deidentified demographic information was also collected. Participants were not asked to provide any information about their Medicare Part D plan.

Medicare Part D prescription drug plans and Medicare Advantage prescription drug plans that had representatives serving in the AMCP MTM advisory group, who were able 
Findings from a National Survey of Medicare Beneficiary Perspectives on the Medicare Part D Medication Therapy Management Standardized Format

TABLE 1 Demographics and Health Status of Survey Participants ( $N=434$ )

\begin{tabular}{|c|c|c|c|c|}
\hline Baseline Characteristics & n (\%) & Baseline Characteristics & \multicolumn{2}{|c|}{ n (\%) } \\
\hline \multicolumn{2}{|l|}{ Age } & \multicolumn{3}{|l|}{ Geographic region } \\
\hline$<65$ years & $45 \quad(10.37)$ & South & 92 & $(21.20)$ \\
\hline $65-74$ years & $164 \quad(37.79)$ & West & 114 & $(26.27)$ \\
\hline $75-84$ years & $90 \quad(20.74)$ & Did not respond & 140 & $(32.26)$ \\
\hline$>85$ years & $(3.00)$ & \multicolumn{3}{|l|}{ Number of medications } \\
\hline Prefer not to say & $(0.69)$ & $0-4$ & 15 & $(3.46)$ \\
\hline Did not respond & $(27.42)$ & $5-9$ & 84 & $(19.35)$ \\
\hline Race/ethnicity & & $10-14$ & 107 & $(24.65)$ \\
\hline Black/African American & $(2.76)$ & $15-19$ & 43 & $(9.91)$ \\
\hline White & $260 \quad(59.91)$ & $20+$ & 22 & $(5.07)$ \\
\hline Hispanic or Latino & $13 \quad(3.00)$ & Did not respond & 163 & $(37.56)$ \\
\hline Native Hawaiian or Other Pacific Islander & $0 \quad(0.00)$ & \multicolumn{3}{|l|}{ Self-health rating } \\
\hline Asian & $10 \quad(2.30)$ & Poor & 17 & $(3.92)$ \\
\hline American Indian or Alaska Native & $(0.46)$ & Fair & 102 & $(23.50)$ \\
\hline Other & $(0.92)$ & Good & 148 & $(34.10)$ \\
\hline Prefer not to say & $18 \quad(4.15)$ & Very good & 43 & $(9.91)$ \\
\hline Did not respond & $117 \quad(26.96)$ & Excellent & 8 & $(1.84)$ \\
\hline Gender & & Did not respond & 116 & $(26.73)$ \\
\hline Female & $155 \quad(35.71)$ & \multicolumn{3}{|l|}{ Comorbidities } \\
\hline Male & $159 \quad(36.64)$ & Diabetes/high blood pressure & 219 & $(50.46)$ \\
\hline Prefer not to say & $2 \quad(0.46)$ & High cholesterol (dyslipidemia) & 187 & $(43.09)$ \\
\hline Did not respond & $118 \quad(27.19)$ & Heart problems & 117 & $(26.96)$ \\
\hline \multicolumn{2}{|l|}{ Highest education completed } & Chronic obstructive pulmonary disease & 95 & $(21.89)$ \\
\hline Primary school & $2 \quad(0.46)$ & Asthma & 81 & $(18.66)$ \\
\hline Some high school, no diploma & $6 \quad(1.38)$ & Depression & 73 & $(16.82)$ \\
\hline High school diploma (or GED) & $82 \quad(18.89)$ & Irregular heart rate (atrial fibrillation) & 72 & $(16.59)$ \\
\hline College or higher & $213 \quad(49.08)$ & Chronic heart failure & 42 & $(9.68)$ \\
\hline Prefer not to say & $12 \quad(2.76)$ & Osteoporosis & 42 & (9.68) \\
\hline Did not respond & $119 \quad(27.42)$ & Rheumatoid arthritis & 42 & (9.68) \\
\hline \multicolumn{2}{|l|}{ Geographic region } & Memory problems (dementia) & 19 & $(4.38)$ \\
\hline Northeast & $29 \quad(6.68)$ & Other & 105 & $(24.19)$ \\
\hline Midwest & $59 \quad(13.59)$ & Did not respond & 124 & $(28.57)$ \\
\hline
\end{tabular}

to participate in this research, distributed the surveys electronically to beneficiaries' email addresses of record. Plans distributed the electronic link to the survey using SurveyMonkey to a sample of Medicare beneficiaries who had received a CMR in the past year. Survey distribution began on July 1, 2018, and data collection ended on October 31, 2018. There were no incentives offered; some plans sent reminder emails. Additionally, on the landing page before entering the survey, participants were directed to call the University of Maryland research team if assistance with completing the survey was desired.

\section{Data Analysis}

The descriptive analysis included all unduplicated surveys in the counts, irrespective of the completeness or recollection of receiving the SF. Duplicated surveys were identified by the Internet protocol address of the electronic survey submission, and in all instances, the most complete (i.e., the survey with the highest number of answered questions) survey response was retained for inclusion in the analysis. Nonresponders (i.e., participants who skipped 1 or more questions) were included in the denominator and also described as a separate category ("Did not respond/Skipped") for each question. Counts and percentages were reported for demographic and clinical information (i.e., age, race, gender, ZIP code, education, comorbidities, number of medications) and self-reported health status. Using participant-reported ZIP codes, the participant's geographic state was identified and then categorized into geographic regions as delineated by the U.S. Census Bureau. ${ }^{11}$ Counts and percentages are also reported for the perceived value and helpfulness of the SF and its 3 components (cover letter, MAP, and PML), along with beneficiaries' opinions on updates to the SF, alternate formatting of the SF, and integration of the SF with health records. Correlation analyses were conducted to assess the relationship between ratings of 


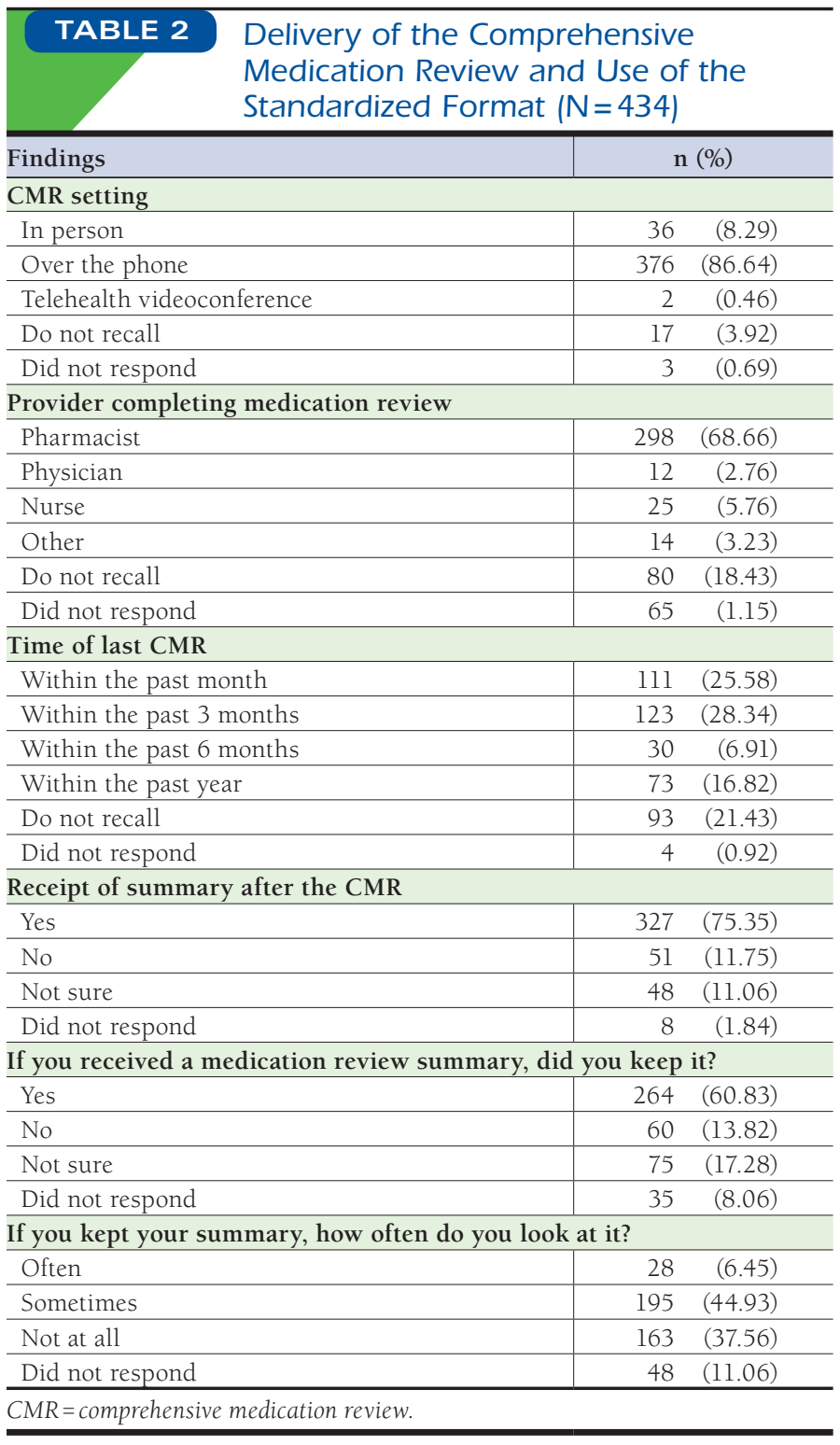

specific aspects of the SF and overall ratings of the CMR service and the overall rating of the MTM service with demographic information including age, race/ethnicity, gender, education, and specific variables of interest, such as number of medications and self-reported health status. For the correlation analyses, a Pearson's coefficient of 0.70 or higher was noted and a $P$ value of $<0.05$ was considered significant. Statistical analyses were performed using SAS statistical software, version 9.4 (SAS Institute, Cary, NC). This study was reviewed and approved by the University of Maryland, Baltimore, Institutional Review Board (IRB\#HP00077628).

\section{Results}

From July 1, 2018, through October 31, 2018, 434 unduplicated surveys were received, resulting in a survey response of 4.3\%. The completion rate for the 434 surveys was $71 \%$.

\section{Demographic Information and Health Status}

Of the 434 electronic survey respondents, which included beneficiaries or their caregivers $(n=23), 37.8 \%$ were aged 65-74 years; $60 \%$ were white; and $49.1 \%$ had at least a college education (Table 1). The most commonly reported comorbidities were diabetes (50.5\%) and high cholesterol (43.1\%), with $10.7 \%$ rating their health as very good or excellent and $27.4 \%$ choosing poor or fair. About one fourth of respondents did not provide an answer for every question in this section, which may be partially explained by the fact that these questions were at the end of the survey.

\section{Beneficiaries' Self-Reported Information on Medication Reviews}

The CMR had been conducted via telephone for $86.6 \%$ of respondents and completed by a pharmacist in $68.7 \%$ of surveys (Table 2). More than half of respondents had their last CMR within the past 3 months, but approximately 1 of every $5(21.4 \%)$ could not recall when they had their last CMR. Although $75.4 \%$ noted they received an SF after their review, $11.8 \%$ said they had not received one, and another $11.1 \%$ were not sure. A majority of respondents (60.8\%) kept their SFs. In terms of repeated use of the SF, 44.9\% looked at the SF sometimes; 6.5\% looked at it often; and 37.6\% did not look at it at all.

There was a high degree of correlation between 7 questions evaluating the usefulness of the SF and the overall rating of the MTM service. There was a significant correlation between overall rating of the medication review and 4 questions based on various uses of the SF, that is, help in understanding the medications, keeping track of the medications, correct use of medications, and solving problems related to medications $(r \geq 0.70, P<0.001)$ There was also a significant correlation $(r \geq 0.50, P<0.001)$ between 3 questions on usefulness of the MAP and overall rating of the medication review. There was no significant correlation between the overall rating of the service and demographic information (i.e., age, gender, or education level) or the number of medications.

\section{Ratings of the SF and Value of the MTM Services}

Using "poor," "fair," "good," "very good," or "excellent," survey respondents were asked to rate how well the SF helped them with managing their medications, such as providing a better understanding of the medications, using them correctly, and tracking and solving any potential medication-related problems (Figure 1). Responses of "very good" to "excellent" ranged from $40.8 \%$ to $44.9 \%$ for the 4 questions and "poor" to "good" from $43.8 \%$ to $48.4 \%$. Approximately $10 \%$ did not respond. 
Findings from a National Survey of Medicare Beneficiary Perspectives

on the Medicare Part D Medication Therapy Management Standardized Format

\section{FIGURE 1 Ratings of the Standardized Format Based on Its Various Uses}

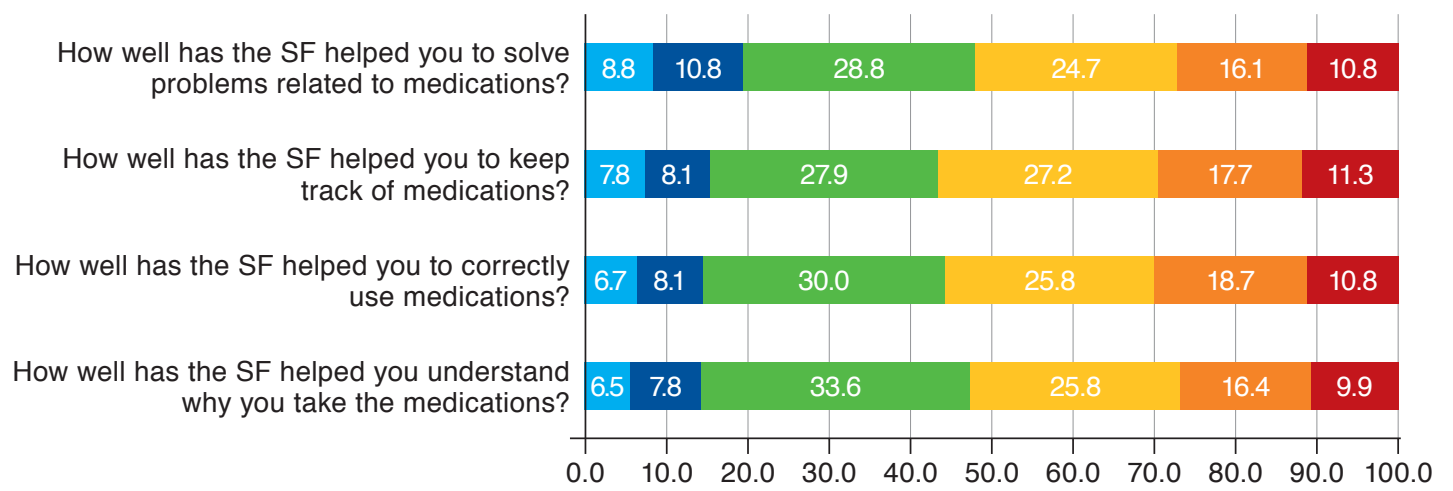

Poor Fair Good Very good Excellent Did not respond

SF = Standardized Format.

Respondents rated MTM service "very good" to "excellent" (41.7\%) and 31.3\% "good" to "poor." However, 63\% of respondents would recommend the MTM service to friends or relatives who needed help with their medications.

\section{Opinions on Individual Sections of the SF}

Most respondents (52.5\%) found the cover letter helpful, and $35.3 \%$ preferred that the cover letter be kept in the SF. Between 47.5\% and 50.5\% found the MAP and the sections "What we talked about" and "What I need to do" helpful. However, 48.6\% reported they did not write anything in the fill-in sections of the MAP. Furthermore, only $35.5 \%$ of respondents preferred keeping the MAP in the SF, whereas $31.8 \%$ had no preference, and another $20.1 \%$ skipped the question or did not respond.

The PML garnered more long-term utility, with $44.7 \%$ of the respondents reporting that they update their PMLs, and 14.3\% reporting that they do not. The most useful sections of the PML were medication name, strength, dosage form, and "How and why I use the medication" (Figure 2). One in 4 (25.8\%) preferred a vertical page format, and $22.6 \%$ preferred a horizontal page format; approximately half had no preference or skipped the question.

Participants expressed interest in adding information to the PML on common drug interactions (39.6\%), side effects (40.3\%), and special instructions (40.3\%). Furthermore, 34.8\% requested information about alternative medications in the same class that could be cheaper.

\section{Delivery and Integration}

When asked for their opinion regarding the integration of the medication summary into their health records, over half $(55.3 \%)$ of respondents were in favor, while $9.4 \%$ were against it, and $9.9 \%$ were not sure (Table 3). In addition, $42.9 \%$ felt that an electronic copy of the SF would be helpful.
The majority (54.6\%) of respondents reported that they would use a wallet card if available and would prefer it be filled out with their information before receiving it (62.4\%). When they were asked about what information they would like included on the wallet card, the most popular responses were prescription medications (64.1\%), followed by medical conditions (50.2\%) and alerts for emergency personnel, such as "patient is receiving blood thinners" (47.9\%).

Finally, 30\% of respondents brought their SFs to their doctors, and 39.6\% did not; $26 \%$ gave copies of their SFs to their relatives, and $46.1 \%$ did not.

\section{Discussion}

If requirements for Medicare eligibility remain the same, the Medicare population is expected to increase from 54 million in 2015 to more than 80 million beneficiaries in 2030. This increased population will likely result in an increased number of beneficiaries receiving the SF as part of the CMR service. There is growing importance in understanding the Medicare beneficiary perspective on the value and utility of the SF, as well as the MTM service, to improve medication-related outcomes. The findings from this study, the largest study to date to gather beneficiary perceptions of the Medicare Part D MTM $\mathrm{SF}$, can provide insight into modernizing the MTM program. Because there were significant correlations between overall rating and recommendation for the MTM service with key questions from the survey, these results suggest that the SF is a meaningful part of the medication review service and that improving sections of the SF may improve overall ratings of the MTM service. While 63\% of the 434 respondents in this survey would recommend the MTM service to their friends or relatives if they needed help with their medications, only between $40 \%$ and $45 \%$ rated the SF as very good or excellent. 


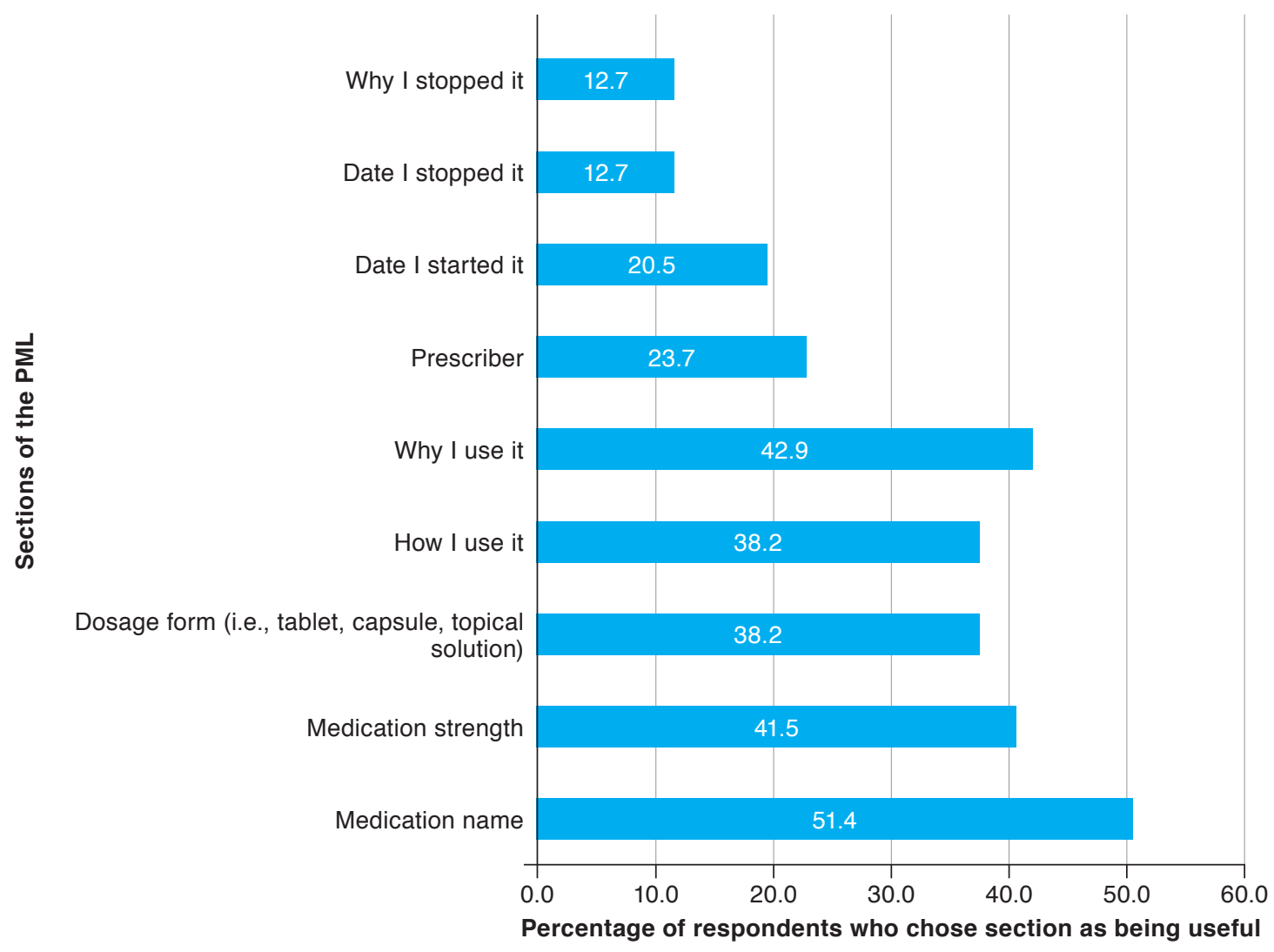

PML= personal medication list.

All components of the SF contained essential elements, but Medicare beneficiaries shared their perspectives on how to improve the SF. Based on the results of this study, there are several recommendations to address beneficiary needs for each component of the SF:

- Cover Letter: No modifications suggested.

- Medication Action Plan: Remove the sections "What I did and when I did it"; "My follow-up plan"; and "Questions I want to ask," that is, all sections that require the beneficiary to fill them out.

- Personal Medication List: Remove the sections "Date I started" and "Date I stopped and why." Further evaluate the Prescriber field. Create beneficiary-friendly mechanisms for more timely updates (e.g., health record portal).

However, these recommendations appear to make cuts or additions to the existing SF that may be short sighted. This is not the intent of these recommendations, but a beginning to identify helpful data elements that are meaningful to beneficiaries and facilitate integration. Layout and design of health information are important; thus, we included such items as part of our approach to measuring specific features of SF. ${ }^{12}$ Beneficiaries and health care providers support the integration of the SF into existing electronic health and medication records, yet there is no consensus on what the SF should "look like." Rather, action should be taken to have consistent domains (i.e., data elements) that can be adapted to meet the needs of the beneficiary and his or her caregiver. For example, these changes would allow a modifiable printout (e.g., wallet card) for beneficiary and/ or caregiver access, such as the current program available at eMedicare. Transforming the SF into interoperable elements meaningful to the beneficiary would help address integration and improve goal attainment of increased medication effectiveness and safety for Medicare Part D beneficiaries. ${ }^{13,14}$ However, there were $9.4 \%$ of Medicare beneficiaries who did not want this information integrated into their medical records. These findings are consistent with previous research on consumer attitudes regarding health information exchange. Although a majority support the use of health information exchange owing to perceived benefits, there are those who do not, likely due to privacy/security concerns. ${ }^{15,16}$ Furthermore, engaging Medicare 


\section{TABLE 3 Opinions on Integration and Format of} the Standardized Format

\begin{tabular}{|c|c|c|}
\hline Questions on Integration and Format $(\mathrm{N}=434)$ & & (\%) \\
\hline \multicolumn{3}{|l|}{ Your opinion on the length of the summary } \\
\hline Too long & 47 & $(10.83)$ \\
\hline Too short & 2 & $(0.46)$ \\
\hline Just the right length & 215 & $(49.54)$ \\
\hline Not sure & 58 & $(13.36)$ \\
\hline Skipped/did not respond & 112 & $(25.81)$ \\
\hline \multicolumn{3}{|l|}{ Would you use a wallet card, if one was provided? } \\
\hline Yes & 237 & $(54.61)$ \\
\hline No & 51 & $(11.75)$ \\
\hline Unsure & 46 & $(10.60)$ \\
\hline Skipped/did not respond & 100 & $(23.04)$ \\
\hline \multicolumn{3}{|c|}{ What information would you like to be included on the wallet card? } \\
\hline Prescription medications & 278 & $(64.06)$ \\
\hline $\begin{array}{l}\text { Alert medications for emergency personnel } \\
\text { (e.g., use of blood thinner) }\end{array}$ & 208 & $(47.93)$ \\
\hline Over-the-counter medications & 110 & $(25.35)$ \\
\hline Allergies & 179 & $(41.24)$ \\
\hline Medical conditions & 218 & $(50.23)$ \\
\hline Other (please specify) & 18 & $(4.15)$ \\
\hline Skipped/did not respond & 119 & $(27.42)$ \\
\hline \multicolumn{3}{|c|}{ Do you bring your medication review summary to your doctor visit? } \\
\hline Yes & 131 & (30.18) \\
\hline No & 172 & $(39.63)$ \\
\hline Not sure & 22 & $(5.07)$ \\
\hline Skipped/did not respond & 109 & $(25.12)$ \\
\hline \multicolumn{3}{|c|}{ Do you give copies of your medication summary to your relatives? } \\
\hline Yes & 113 & $(26.04)$ \\
\hline No & 200 & $(46.08)$ \\
\hline Not sure & 10 & $(2.30)$ \\
\hline Skipped/did not respond & 111 & $(25.58)$ \\
\hline
\end{tabular}

beneficiaries and/or caregivers with CMR follow-up and the SF encourages them to be active in their health care decisions and promotes patient-centered care. ${ }^{17}$

\section{Limitations}

The primary limitation of this study is the response rate of $4.3 \%$, which is lower than the historic rate for the Medicare prescription drug plan Consumer Assessment of Healthcare Providers and Systems survey. ${ }^{18}$ Web surveys such as ours are more efficient but typically have lower response rates compared with mailed surveys. ${ }^{19}$ As of 2016, approximately 65\% of Medicare beneficiaries indicated that they use the Internet daily or almost daily, ${ }^{20}$ but it is unclear how many surveys reached the intended recipients, owing to the inaccuracy of email addresses on record, or were opened, owing to incompatibility with technology used to access emails.

Despite the relatively low response, the race, age, and other demographics presented are reflective of the greater Medicare beneficiary population. For instance, $60 \%$ of our respondents were white, and according to the Medicare Payment Advisory Committee report, $74 \%$ of beneficiaries are white. Further, $40 \%$ of our respondents had a college or postgraduate education, whereas 19\% had a high school diploma only, compared with national estimates of 54\% and 28\% respectively. ${ }^{21}$ Additional research is needed to confirm these findings.

Although recall bias is a concern with surveys, this aspect was minimized by limiting those eligible for inclusion to those who had had a CMR within the past year. Participating Part D plans were asked to sample from those beneficiaries who had a CMR within the past year. Future studies should continue to engage the Medicare beneficiary in codesign of health care services and format of medication information.

\section{Conclusions}

Fewer than half of the Medicare beneficiary respondents perceived the SF as very good or excellent with helping to manage their medications. This national survey, the largest to date, provides Medicare beneficiary-focused evidence that more work needs to be done to improve the usability and portability of the SF. These aspects can be achieved by allowing flexibility in the design of the SF while requiring essential elements. MTM programs need to integrate the SF into health records and allow a modifiable printout available (e.g., wallet card and other digital, user-friendly formats).

\section{Authors}

NICOLE J. BRANDT, PharmD, MBA, BCGP; CATHERINE E. COOKE, PharmD, BCPS, PAHM; KRITI SHARMA, MD, MPH; and JOSHUA CHOU, PharmD, University of Maryland School of Pharmacy, Baltimore. MARY JO CARDEN, RPh, JD, and PATTY KUMBERA, RPh, Academy of Managed Care Pharmacy, Alexandria, Virginia. KAREN PELLEGRIN, PhD, MBA, University of Hawaii at Hilo.

AUTHOR CORRESPONDENCE: Nicole J. Brandt, PharmD, MBA, BCGP, University of Maryland School of Pharmacy, The Lamy Center, 220 Arch St., 12th Fl., Baltimore, MD 21201. Tel.: 410.706.1491; E-mail: nbrandt@rx.umaryland.edu.

\section{DISCLOSURES}

This study was funded by the Academy of Managed Care Pharmacy (AMCP), which provided a grant to the University of Maryland School of Pharmacy to conduct this study. Carden and Kumbera are AMCP employees. Brandt reports a grant from IMPAQ and consulting fees from Rand, outside of this study. Pellegrin is a member of the AMCP MTM Advisory Board. The other authors have nothing to disclose.

\section{REFERENCES}

1. Centers for Medicare \& Medicaid Services. Part D medication therapy management (MTMP) program. Modified January 23, 2019. Available at: https://www.cms.gov/medicare/prescription-drug-coverage/prescriptiondrugcovcontra/mtm.html. Accessed February 6, 2019. 
2. Centers for Medicare \& Medicaid Services. Medicare Part D medication therapy management standardized format. Revised August 15, 2012. Available at: https://www.cms.gov/Medicare/Prescription-Drug-Coverage/ PrescriptionDrugCovContra/Downloads/MTM-Program-StandardizedFormat-English-and-Spanish-Instructions-Samples-.pdf. Accessed February 6, 2019.

3. Gabriel MH, Smith JY, Sow M, Charles D, Joseph S, Wilkins TL. Dispatch from the non-HITECH-incented Health IT world: electronic medication history adoption and utilization. J Am Med Inf Assoc. 2015;23(3):562-69.

4. Swain M, Charles D, Patel V, Searcy T. Health information exchange among US non-federal acute care hospitals: 2008-2014. ONC Data Brief No. 17. May 2014. Available at: https://www.healthit.gov/sites/default/files/ oncdatabrief17_hieamonghospitals.pdf. Accessed February 6, 2019.

5. Cooke C, Kaiser M, Natarajan N, Brandt N. Medicare beneficiary satisfaction with comprehensive medication review and the standardized format. J Manag Care Spec Pharm. 2015;21(10-a):S79-S80 [Abstract U29]. Available at: https://www.jmcp.org/doi/pdf/10.18553/jmcp.2015.21.10.S1.

6. Cantrell SA; Academy of Managed Care Pharmacy. Re: CMS-10396 medication therapy management program improvements. December 30, 2016. Available at: http://www.amcp.org/WorkArea/DownloadAsset. aspx?id=21758. Accessed February 6, 2019.

7. Snyder ME, Jaynes, HA Gernant SA, Lantaff WM, Hudmon KS, Doucette WR. Variation in medication therapy management delivery: implications for health care policy. J Manag Care Spec Pharm. 2018;24(9):896-902. Available at: https://doi.org/10.18553/jmcp.2018.24.9.896.

8. Crow R, Gage H, Hampson S, et al. The measurement of satisfaction with healthcare: implications for practice from a systematic review of the literature. Health Technol Assess. 2002;6(32):1-244.

9. Sharma K, Cooke CE, Howard A, Chater R, Vogler A, Brandt NJ. Beneficiarydriven changes to the Part D medication therapy management standardized format. J Manag Care Spec Pharm. 2018;24(10-a):S95 [Abstract U26]. Available at: https://www.jmcp.org/doi/pdf/10.18553/jmcp.2018.24.10-a.sl.

10. Ware JE Jr, Hays RD. Methods for measuring patient satisfaction with specific medical encounters. Med Care. 1988;26(4):393-402.
11. U.S. Census Bureau. Geographic terms and concepts—census divisions and census regions. Revised February 9, 2015. Available at: https://www.census.gov/geo/reference/gtc/gtc_census_divreg.html. Accessed February 6, 2019. 12. Centers for Disease Control and Prevention. Simply put: a guide for creating easy-to-understand materials. 2009. Available at: https://www.cdc.gov/ healthliteracy/pdf/simply_put.pdf. Accessed February 6, 2019.

13. Ogle SM, Cooke CE, Brandt NJ. Medication management and e-care planning: what are the opportunities for the future? J Geron Nur. 2015;41(10):13-17.

14. Look KA, Stone JA. Medication management activities performed by informal caregivers of older adults. Res Soc Admin Pharm. 2018;14(5):418-26.

15. Dimitropoulos L, Patel V, Scheffler SA, Posnack S. Public attitudes toward health information exchange: perceived benefits and concerns. Am J Manag Care. 2011;17(12 Spec No.):SP111-SP116.

16. Ancker JS, Edwards AM, Miller MC, Kaushal R. Consumer perceptions of electronic health information exchange. Am J Prev Med. 2012;43(1):76-80.

17. Schulte N, Ruisinger JF, Prohaska ES, Steele KM, Melton BL.

Comprehensive medication review recipients opinions, actions, and information recall. J Am Pharm Assoc. 2017;57(3):407-11.

18. Centers for Medicare \& Medicaid Services. Medicare Advantage and prescription drug plan CAHPS survey. Modified January 30, 2019. Available at: https://www.ma-pdpcahps.org/en/historic-data/. Accessed February 6, 2019.

19. Tesler R, Sorra J. CAHPS survey administration: what we know and potential research questions. Available at: https://www.ahrq.gov/sites/ default/files/wysiwyg/cahps/about-cahps/research/survey-administrationliterature-review.pdf. Accessed February 6, 2019.

20. Centers for Medicare \& Medicaid Services. eMedicare-another step to strengthening Medicare! [blog]. October 18, 2018. Available at: https:// www.medicare.gov/blog/emedicare-another-step-to-strengthening-medicare. Accessed February 6, 2019.

21. Medicare Payment Advisory Commission. A data book: healthcare spending and the Medicare program. June 2018. Available at: http://medpac.gov/docs/default-source/data-book/jun18_databookentirereport_sec. pdf?sfvrsn=. Accessed February 6, 2019. 
Findings from a National Survey of Medicare Beneficiary Perspectives on the Medicare Part D Medication Therapy Management Standardized Format

Greetings! You or someone you care for recently had a medication review by a pharmacist or other provider as part of the Medicare Part D prescription drug plan. After reviewing all of your medications and how to take them, you should have received a summary document of that review. This medication review summary includes: a cover letter, personal medication list, and medication action plan. We want to learn which parts of the summary are most useful to you and what role you feel the summary should play in your care.

If you have your medication review summary handy, you may find it helpful as a reference while you complete this survey. Here is an example of the cover letter:

$01 / 01 / 2016$

Dear Mr. John Doe:

Thank you for talking with me on 12/28/2015 about your health and medications. Medicare's MTM (Medication Therapy Management) program helps you make sure that your medications are working. Along with this letter are an action plan (Medication Action Plan) and a medication list (Personal Medication List). The action plan has steps you should take to help you get the best results from your medications. The medication list will help you keep track of your medications and how to use them the right way.

- Have your action plan and medication list with you when you talk with your doctors, pharmacists, and other health care providers.

- Ask your doctors, pharmacists, and other healthcare providers to update them at every visit.

This survey should take no more than 25 minutes to complete. All survey responses are anonymous. Individual responses will not be made available to your health insurance provider. This survey has been approved by the Institutional Review Board at the University of Maryland Baltimore. If you have additional questions, please contact the Principal Investigator, Dr. Nicole Brandt, at nbrandt@rx.umaryland.edu or 410-706-1491. Thank you for your time and feedback completing the survey. 
Findings from a National Survey of Medicare Beneficiary Perspectives on the Medicare Part D Medication Therapy Management Standardized Format

\section{APPENDIX Medication Review Summary Satisfaction Survey (continued)}

\section{Please tell us about your medication review.}

We would like to know more about the medication review you had with a pharmacist or other healthcare provider.

(1) Who had a recent medication review?

Me (the Medicare Part D member)

Me (I also had a caregiver there to help)

Caregiver on behalf of a member (I am taking the survey as the caregiver)

Other (please specify)

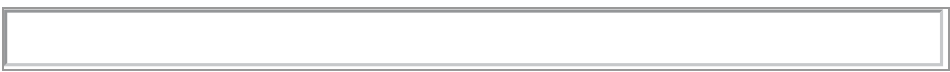

(2) How did you have your medication review?

In person

Over the phone

Telehealth videoconference

Do not recall

(3) Which type of provider completed your medication review?

A pharmacist

A physician

A nurse

Do not recall

Other (please specify)

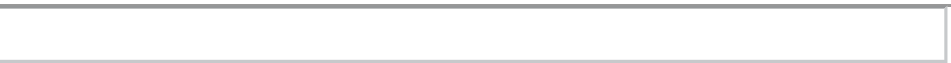


Findings from a National Survey of Medicare Beneficiary Perspectives on the Medicare Part D Medication Therapy Management Standardized Format

\section{APPENDIX Medication Review Summary Satisfaction Survey (continued)}

4 When was your last medication review?

Within the past month

Within the past 3 months

Within the past 6 months

Within the past year

Do not recall

\section{Please tell us more about the medication review summary overall.}

Note: You may find it helpful to have your medication review summary on hand as you complete this survey. You can refer to your summary when answering any of the questions.

5 Did you receive a medication review summary?

Yes

No

Not sure

6 If you received a medication review summary, did you keep it?

Yes

No

Not sure

(7) If you kept your summary, how often do you look at it?

Often

Sometimes

Not at all 
Findings from a National Survey of Medicare Beneficiary Perspectives on the Medicare Part D Medication Therapy Management Standardized Format

APPENDIX Medication Review Summary Satisfaction Survey (continued)

Please tell us more about the overall value of your medication review summary.

We would like you to rate how well the medication review summary has helped you in the following areas --

8) How well has the medication review summary helped you to understand why you are taking your medications?
Poor
Fair
Good
Very Good
Excellent

9) How well has the medication review summary helped you to correctly take your medications (for example: at the correct time, with or without food)
Poor
Fair
Good
Very Good
Excellent

(10) How well has the medication review summary helped you to keep track of what medications you are taking?

\section{Poor}

Fair

Good

Very Good

Excellent 
Findings from a National Survey of Medicare Beneficiary Perspectives on the Medicare Part D Medication Therapy Management Standardized Format

(11) How well has the medication review summary helped you to solve any medication problems found during the medication review (for example: drug-drug interactions, side effects)?

Poor

Fair

Good

Very Good

Excellent

Please give us feedback on the medication review summary content and usefulness

Questions 12-13 will ask about the cover letter from the medication review summary. Example:

$01 / 01 / 2016$

Dear Mr. John Doe:

Thank you for talking with me on 12/28/2015 about your health and medications. Medicare's MTM (Medication Therapy Management) program helps you make sure that your medications are working. Along with this letter are an action plan (Medication Action Plan) and a medication list (Personal Medication List). The action plan has steps you should take to help you get the best results from your medications. The medication list will help you keep track of your medications and how to use them the right way.

- Have your action plan and medication list with you when you talk with your doctors, pharmacists, and other health care providers.

- Ask your doctors, pharmacists, and other healthcare providers to update them at every visit.

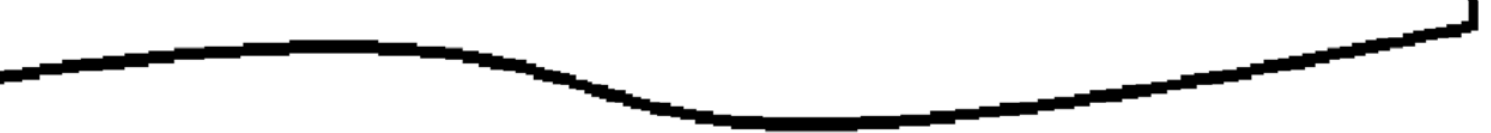

(12) Does the cover letter include helpful information?
Yes
No
Not sure 
Findings from a National Survey of Medicare Beneficiary Perspectives on the Medicare Part D Medication Therapy Management Standardized Format

13 What is your preference about the cover letter?

Keep the cover letter in the summary

Make the cover letter shorter

Include more information in the cover letter

Remove the cover letter in the summary

No preference

Please give us feedback on the medication summary content and usefulness

Questions 14-18 will ask about the medication action plan in the medication review summary.

\section{Example:}

MEDICATION ACTION PLAN FOR Joe Doe, DOB: 01/01/1941

This action plan will help you get the best results from your medications if you:

1. Read "What we talked about."

2. Take the steps listed in the "What I need to do" boxes.

3. Fill in "What I did and when I did it." 4. Fill in "My follow-up plan" and "Questions I want to ask."

Have this action plan with you when you talk with your doctors, pharmacists, and other healthcare providers. Share this with your family or caregivers too.

DATE PREPARED: 01/01/2016

\begin{tabular}{|l|l|}
\hline What we talked about: \\
\hline What I need to do: & What I did and when I did it: \\
\hline
\end{tabular}

My follow-up plan:

Questions I want to ask: 
Findings from a National Survey of Medicare Beneficiary Perspectives on the Medicare Part D Medication Therapy Management Standardized Format

APPENDIX

Medication Review Summary Satisfaction Survey (continued)

(14) Which section(s) of the medication action plan did you fill out?

Please select all that apply.

$\square$ "What I did and when I did it"

"My follow-up plan"

$\square$ "Questions I want to ask"

None

$\square$ Not sure

(15) Do you find the "What we talked about" in the medication action plan helpful?

Yes

No

Not sure

(16) Do you find the "What I need to do" in the medication action plan helpful?

Yes

No

Not sure

(17) Do you find the medication action plan helpful overall?

Yes

No

Not sure 
Findings from a National Survey of Medicare Beneficiary Perspectives on the Medicare Part D Medication Therapy Management Standardized Format

(18) What is your preference about the medication action plan?

Keep the medication action plan in the summary

Make the medication action plan shorter

Include more information in the medication action plan

Remove the medication action plan in the summary

No preference

Please give us feedback on the medication review summary content and usefulness

Questions 19-22 will ask about the personal medication list in the medication review summary.

Example:

PERSONAL MEDICATION LIST FOR John Doe, DOB: 01/01/1941

(Continued)

Medication: Metoprolol Succinate ER Oral Tablet Extended Release 24 Hour $25 \mathrm{MG}$

How I use it: Take one tablet by mouth every day

Why I use it: Heart Failure

Date I started using it: Date I stopped using it:

Why I stopped using it:

Medication: Spironolactone Oral Tablet $25 \mathrm{MG}$

How I use it: Take one tablet by mouth every morning

Why I use it: Heart Failure

Date I started using it: Date I stopped using it:

Why I stopped using it: 
Findings from a National Survey of Medicare Beneficiary Perspectives on the Medicare Part D Medication Therapy Management Standardized Format

\section{APPENDIX Medication Review Summary Satisfaction Survey (continued)}

(19) What information currently included in the personal medication list do you find helpful?

Please select all that apply.

Medication name

$\square$ Medication strength

Dosage form (for example: tablet, capsule, topical solution)

How I use it

Why I use it

Prescriber

Date I started using it

Date I stopped using it

$\square$ Why I stopped using it

20 What other information, if any, would you find helpful to have in the personal medication list?

Please select all that apply.

$\square$ Common drug interactions

$\square$ Common side effects

Special instructions (for example: with or with food)

$\square$ Available alternatives -- other medications in the same drug class that may be cheaper

$\square$ Other (please specify)

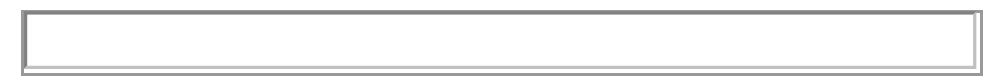


Findings from a National Survey of Medicare Beneficiary Perspectives on the Medicare Part D Medication Therapy Management Standardized Format

21 How would you prefer to see the personal medication list presented in the medication review summary?

A) Horizontal

John Doe

DOB: 01/01/1941
Created: 01/01/1941

Prepared by: Jane Smith, PharmD

\section{MY MEDICATION INFORMATION}

Medications that I take (prescription, non-prescription, natural health products, homeopathic remedies)

\begin{tabular}{|c|c|c|c|c|c|}
\hline Medication & How I use it & Why I use it & $\begin{array}{l}\text { Date I } \\
\text { started } \\
\text { using it }\end{array}$ & $\begin{array}{l}\text { Date I } \\
\text { stopped } \\
\text { using it }\end{array}$ & Why I stopped using it \\
\hline $\begin{array}{l}\text { Metoprolol Succinate ER } \\
\text { Oral Tablet Extended } \\
\text { Release } 24 \text { Hour } 25 \mathrm{mg}\end{array}$ & Take one tablet by mouth every day & Heart Failure & & & \\
\hline $\begin{array}{l}\text { Spironolactone Oral } \\
\text { Tablet } 25 \mathrm{mg}\end{array}$ & Take one tablet by mouth every morning & Heart Failure & & & \\
\hline
\end{tabular}

B) Vertical

PERSONAL MEDICATION LIST FOR John Doe, DOB: 01/01/1941

(Continued)

Medication: Metoprolol Succinate ER Oral Tablet Extended Release 24 Hour $25 \mathrm{MG}$

How I use it: Take one tablet by mouth every day

Why I use it: Heart Failure

Date I started using it:

Date I stopped using it:

Why I stopped using it:

Medication: Spironolactone Oral Tablet $25 \mathrm{MG}$

How I use it: Take one tablet by mouth every morning

Why I use it: Heart Failure

Date I started using it:

Date I stopped using it:

Why I stopped using it:

A vertical format

No preference 
Findings from a National Survey of Medicare Beneficiary Perspectives on the Medicare Part D Medication Therapy Management Standardized Format

APPENDIX

Medication Review Summary Satisfaction Survey (continued)

22 What is your preference about the personal medication list overall?

Keep the personal medication list in the summary

Make the personal medication list shorter

Include more information in the personal medication list

Remove the personal medication list in the summary

No preference 
Findings from a National Survey of Medicare Beneficiary Perspectives on the Medicare Part D Medication Therapy Management Standardized Format

\section{APPENDIX Medication Review Summary Satisfaction Survey (continued)}

\section{Additional materials}

Right now the medication review summary includes a cover letter, medication action plan, and personal medication list. We would like to know if there are other materials you would find helpful to manage your medications.

For example a wallet card:

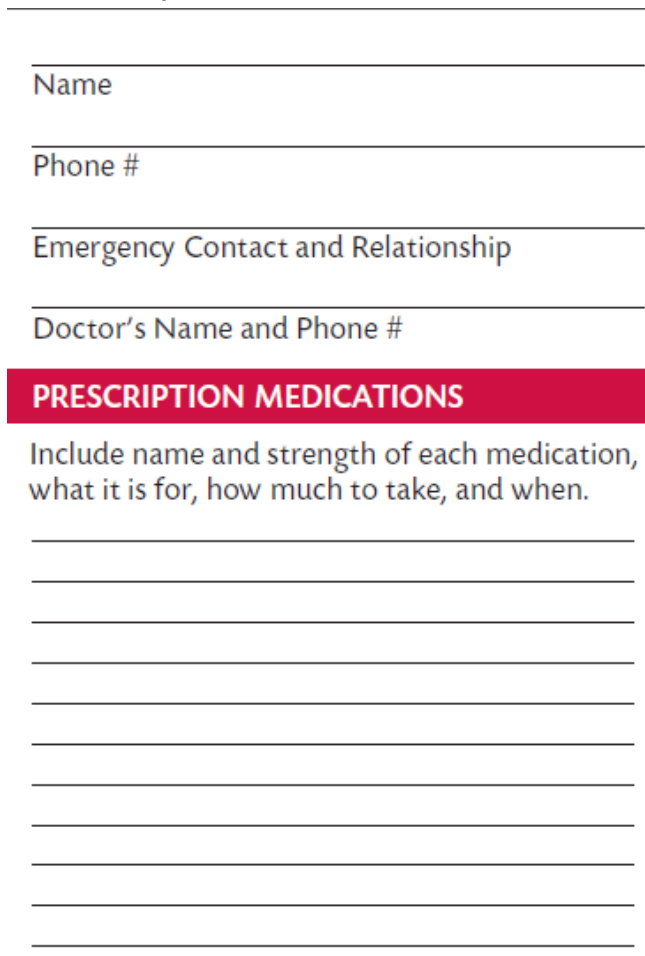

BLOOD THINNER

I take blood thinner medication

\section{OVER-THE-COUNTER MEDICATIONS}

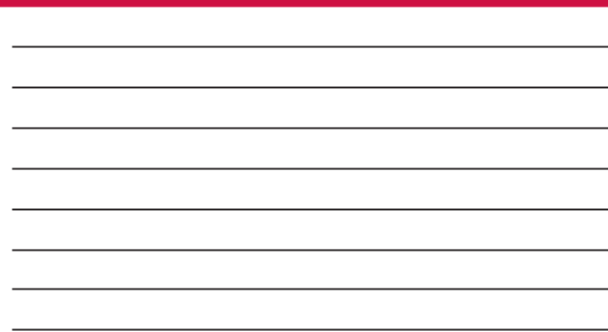

\section{ALLERGIES}

\section{MEDICAL CONDITIONS}

\section{MEDICATION WALLET CARD}

Take this card with you each time you go to the doctor, pharmacist or hospital.

Name of Medication: 
Findings from a National Survey of Medicare Beneficiary Perspectives on the Medicare Part D Medication Therapy Management Standardized Format

\section{APPENDIX Medication Review Summary Satisfaction Survey (continued)}

23 Would you use a wallet card if one was provided in your medication review summary?

Yes

No

Unsure

24. If you were provided with a wallet card, what information would you like to have included on the wallet card?

Please select all that apply.

Prescription medications

Alert medications for emergency personnel (for example: use of blood thinner)

$\square$ Over the counter medications

$\square$ Allergies

$\square$ Medical conditions

$\square$ Other (please specify)

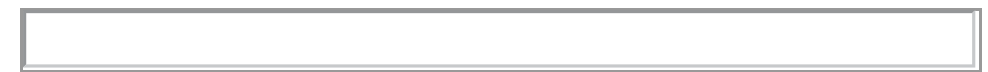

25 Would you prefer the wallet card already be filled out with your information and medications when you get it?

Yes

No

Not sure 
Findings from a National Survey of Medicare Beneficiary Perspectives on the Medicare Part D Medication Therapy Management Standardized Format

\section{APPENDIX Medication Review Summary Satisfaction Survey (continued)}

\section{Please give us feedback on the how you use your medication review summary.}

We would like to know more about who you share the summary with and what role you think these documents should play in your care.

26 Would having an electronic copy of your medication review summary (for example:

through your email, health insurance secured website) be helpful to you?

$$
\begin{aligned}
& \text { Yes } \\
& \text { No } \\
& \text { Not sure }
\end{aligned}
$$

27) Do you bring your medication review summary to your doctor visit?

$$
\begin{aligned}
& \text { Yes } \\
& \text { No } \\
& \text { Not sure }
\end{aligned}
$$

28 Do you give copies of your medication summary to your relatives or caregiver?

$$
\text { Yes }
$$

No

Not sure

29 Do you want your medication review summary to be part of your health record (for example: as part of your personal medical file, accessible by your health care providers)?

$$
\text { Yes }
$$

No

Not sure 
Findings from a National Survey of Medicare Beneficiary Perspectives on the Medicare Part D Medication Therapy Management Standardized Format

\section{APPENDIX Medication Review Summary Satisfaction Survey (continued)}

(30) Do you update the Personal Medication List included in your summary (for example: when you get new prescriptions or your doctor changes the way you take your current medications)?

Yes

No

Sometimes

Not sure

Please provide us with your overall feedback about the medication review summary.

31 Was your last medication review summary too long, too short, or just the right length?

Too long

Too short

Just the right length

Not sure

(32) Overall, how would you rate the medication review you got as part of your Medicare Part $\mathrm{D}$ plan (including the process of reviewing your medications and the documents you received from this review process)?

Poor

Fair

Good

Very Good

Excellent 
Findings from a National Survey of Medicare Beneficiary Perspectives on the Medicare Part D Medication Therapy Management Standardized Format

\section{APPENDIX Medication Review Summary Satisfaction Survey (continued)}

33 If a friend or family member needed help with their medications, would you recommend they complete a medication review?

Yes, Definitely

Yes, Probably

No, Probably not

No, Definitely not

34 What would you change about the medication review summary to help you understand and manage your medications better?

\section{Please tell us a little about yourself.}

We would like to know some basic information about our survey participants. You are not required to provide responses in order to participate further in the survey.

(35) What is your home zip code?

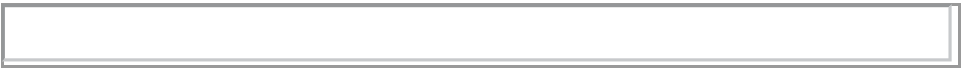

(36) What is your age?

Less than 65

$65-74$

$75-84$

85 or older

Prefer not to say 
Findings from a National Survey of Medicare Beneficiary Perspectives on the Medicare Part D Medication Therapy Management Standardized Format

\section{APPENDIX Medication Review Summary Satisfaction Survey (continued)}

37) What is your gender?

Female

Male

Prefer not to say

Other (please specify)

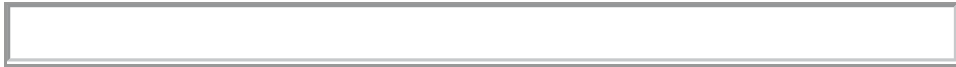

(38) What is your race/ethnicity?

$\square$ Black or African American

$\square$ White

Hispanic or Latino

$\square$ Native Hawaiian or Other Pacific Islander

$\square$ Asian

American Indian or Alaska Native

$\square$ Prefer not to say

$\square$ Other (please specify)

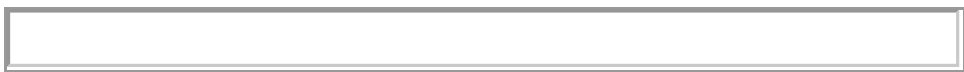

(39) What is the highest level of school that you have completed?

Primary school

Some high school, but no diploma

High school diploma (or GED)

College or higher

Prefer not to say 
Findings from a National Survey of Medicare Beneficiary Perspectives on the Medicare Part D Medication Therapy Management Standardized Format

\section{APPENDIX Medication Review Summary Satisfaction Survey (continued)}

40 Please select which of the following conditions you have (as diagnosed by a healthcare provider):

Asthma

$\square$ Chronic heart failure (CHF)

Chronic obstructive pulmonary disease (COPD)

Depression

$\square$ Diabetes High blood pressure (hypertension)

$\square$ Heart problems

High cholesterol (dyslipidemia)

Irregular heart rate (atrial fibrillation)

Memory problems (dementia)

Osteoporosis

Rheumatoid arthritis

Other (please specify)

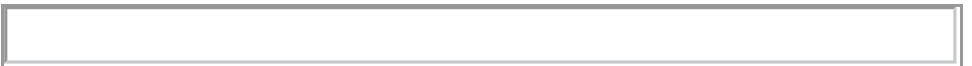

41 How many medications (including over-the-counter, prescriptions, herbals) do you currently take?

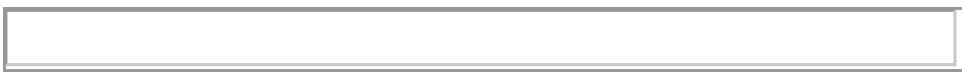

42 During the past 4 weeks, how would you rate your health in general?

Poor

Fair

Good

Very Good

Excellent

Thank you for taking the time to complete this survey. 